\title{
Synthesis of through-space conjugated polymers containing the pseudo-ortho-linked [2.2]paracyclophane moiety
}

\section{$\operatorname{AUTHOR}(\mathrm{S})$ :}

Morisaki, Yasuhiro; Wada, Naoki; Arita, Manabu; Chujo, Yoshiki

\section{CITATION:}

Morisaki, Yasuhiro ...[et al]. Synthesis of through-space conjugated polymers containing the pseudo-ortho-linked [2.2] paracyclophane moiety. Polymer Bulletin 2009, 62(3): 305314

\section{ISSUE DATE:}

2009-03

URL:

http://hdl.handle.net/2433/123391

\section{RIGHT:}

Copyright (C) 2009 Springer; This is not the published version. Please cite only the published version.; この論文は出版社版でありません。引用の 際には出版社版をご確認ご利用ください。 


\title{
Synthesis of Through-space Conjugated Polymers Containing the Pseudo-ortho-linked [2.2]Paracyclophane Moiety
}

\author{
Yasuhiro Morisaki (凶), Naoki Wada, Manabu Arita, Yoshiki Chujo (凶) \\ Department of Polymer Chemistry, Graduate School of Engineering, Kyoto University, Katsura, \\ Nishikyo-ku, Kyoto 615-8510, Japan \\ E-mail: ymo@chujo.synchem.kyoto-u.ac.jp or chujo@chujo.synchem.kyoto-u.ac.jp; Fax: +81 \\ 753832605
}

Received: /Revised version: / Accepted:

\begin{abstract}
Summary
New through-space conjugated polymers comprising the pseudo-ortho-linked [2.2] paracyclophane moiety were synthesized by the Sonogashira coupling reaction. All the synthesized polymers were soluble in common organic solvents and could form thin films. The UV-vis absorption spectra of the synthesized polymers revealed an extension of the conjugation length owing to the through-space interactions. The polymers exhibited a blue-light emission in both solution and film states.
\end{abstract}

\section{Introduction}

[2.2]Paracyclophane has a compelling molecular structure consisting of two co-facial benzene rings in close proximity (ca. 2.8-3.1 $\AA$ ) fixed by two ethylene chains [1]. The transannular electronic interaction between the co-facial benzene rings of [2.2] paracyclophane has attracted considerable attention [2], and a number of [2.2]paracyclophane derivatives have been prepared and characterized [3]. However, despite their potential application as a component of functional polymers, there have been a few studies on the incorporation of [2.2] paracyclophane and its derivatives into the conjugated polymer main chain [4]. Recently, we focused our attention on the synthesis of conjugated polymers comprising [2.2]paracyclophane as the repeating unit in their main chain [5-7]. This synthesis would give rise to a whole new class of conjugated polymers in which the conjugation length is extended via the through-space interaction of the benzene rings. In previous studies, pseudo-para-disubstituted [2.2]paracyclophane was used as the key monomer in the construction of a through-space conjugated framework [5-7].

The following are seven isomers of the disubstituted [2.2]paracyclophane: ortho-, meta-, para-, pseudo-ortho-, pseudo-meta-, pseudo-para-, and pseudo-geminal-disubstituted [2.2]paracyclophanes. Among these isomers, pseudo-para-dibromo[2.2]paracyclophane can be easily obtained from commercially available [2.2]paracyclophane [8]. Thermal isomerization of pseudo-para-dibromo[2.2]paracyclophane thus obtained conveniently affords pseudo-ortho-dibromo[2.2]paracyclophane [8,9]. Therefore, we decided to employ pseudo-ortho-linked [2.2]paracyclophane as a building block for through-space 
conjugated polymers. In this report, we describe the synthesis of novel through-space conjugated polymers comprising pseudo-ortho-linked [2.2] paracyclophane in the main chain and compare the obtained polymer with the polymers possessing the pseudo-para-linked [2.2]paracyclophane units.

\section{Experimental}

\section{General}

${ }^{1} \mathrm{H}$ and ${ }^{13} \mathrm{C}$ NMR were recorded on a JEOL EX270 and 400 instrument at 270 and 400 $\mathrm{MHz}$ and 67.5 and $100 \mathrm{MHz}$, respectively. All samples were analyzed in $\mathrm{CDCl}_{3}$, and chemical shift values were expressed relative to $\mathrm{Me}_{4} \mathrm{Si}$ as an internal standard. UV-vis measurements were carried out on JASCO V-530 spectrophotometer at room temperature. Photoluminescence spectra were recorded on a Perkin-Elmer LS50B luminescence spectrometer at room temperature. Gel permeation chromatography (GPC) was carried out on a TOSOH UV-8020 and RI-8020 (TOSOH TSKgel G3000 column) using $\mathrm{CHCl}_{3}$ as an eluent after calibration with standard polystyrene. Recyclable preparative high-performance liquid chromatography (HPLC) was performed for further purification of polymers on a Japan Analytical Industry Co. Ltd. Model 918R (JAIGEL-2.5H and $3 \mathrm{H}$ columns) using $\mathrm{CHCl}_{3}$ as an eluent. Elemental analyses were performed at the Microanalytical Center of Kyoto University.

\section{Materials}

$\mathrm{Et}_{2} \mathrm{O}$, THF and $\mathrm{NEt}_{3}$ were purified by passage through solvent purification columns under Ar pressure [10]. [2.2]Paracyclophane 1 was purchased from Sigma-Aldrich Co. $n$-BuLi (1.59 $\mathrm{M}$ in hexane) was purchased from Kanto Chemical Co., Inc. $\mathrm{CH}_{2} \mathrm{Cl}_{2}, \mathrm{CCl}_{4}, \mathrm{Br}_{2}, \mathrm{Fe}$, triglyme, $t$-BuOK, and $\mathrm{CuI}$ were purchased from Wako Pure Chemicals Industries. $\mathrm{Pd}\left(\mathrm{PPh}_{3}\right)_{4}$ was purchased from Tokyo Chemical Industry Co., Ltd. Pseudo-para-dibromo[2.2]paracyclophane 2 [8], pseudo-ortho-dibromo[2.2]paracyclophane dibromomethyltriphenylphosphonium 3 bromide pseudo-ortho-diethynyl[2.2]paracyclophane 5 [9c], 2,5-dialkoxy-1,4-diiodobenzenes 6a-c [12], and pseudo-para-diethynyl[2.2]paracyclophane 9 [6f] were synthesized according to the literature. Pseudo-ortho-diformyl[2.2]paracyclophane $\mathbf{4}$ was synthesized according to the literature with minor modification by using DMF as a reagent for formylation instead of formylpiperidine [9c], and the spectral data were matched with the literature's values [9c].

\section{Polymerization}

All of the solid reagents $5(40 \mu \mathrm{mol}), 6(40 \mu \mathrm{mol}), \mathrm{Pd}\left(\mathrm{PPh}_{3}\right)_{4}(9.2 \mathrm{mg}, 8 \mu \mathrm{mol})$, and $\mathrm{CuI}(1.5 \mathrm{mg}, 8 \mu \mathrm{mol})$ were placed in a Schlenk tube equipped with a magnetic stirring bar and a three-way cock. This tube was then purged with Ar followed by introducing THF $(1.2 \mathrm{~mL})$ and $\mathrm{Et}_{3} \mathrm{~N}(1.2 \mathrm{~mL})$. The reaction was carried out at $75^{\circ} \mathrm{C}$ for $48 \mathrm{~h}$. After the reaction, ammonium salt was filtered off with celite and washed with THF. The combined organic solution was concentrated and washed with aqueous $\mathrm{NH}_{3}$ solution (28\%) to remove the inorganic species. The organic layer was dried over $\mathrm{Na}_{2} \mathrm{SO}_{4}$. The condensed organic layer was reprecipitated from $\mathrm{EtOH}$, and 
further reprecipitation from $\mathrm{CHCl}_{3} / \mathrm{EtOH}$ was carried out at least three times to obtain the corresponding polymer as a yellow solid. Further purification by HPLC was carried out for polymers $\mathbf{7 b}$ and $\mathbf{7 c}$.

7a. Yield: 58\%. ${ }^{1} \mathrm{H}$ NMR (400 MHz, $\left.\mathrm{CDCl}_{3}\right): \delta 0.79(\mathrm{~s}, 6 \mathrm{H}), 1.20(\mathrm{~m}, 16 \mathrm{H}), 1.45$ (s, $4 \mathrm{H}), 1.82(\mathrm{~m}, 4 \mathrm{H}), 2.85(\mathrm{br}, 2 \mathrm{H}), 3.04(\mathrm{br}, 2 \mathrm{H}), 3.30(\mathrm{br}, 2 \mathrm{H}), 3.79(\mathrm{br}, 2 \mathrm{H}), 3.91(\mathrm{br}$, $4 \mathrm{H}), 6.53(\mathrm{br}, 4 \mathrm{H}), 7.00(\mathrm{~m}, 2 \mathrm{H}), 7.20(\mathrm{~m}, 2 \mathrm{H}) .{ }^{13} \mathrm{C} \mathrm{NMR}\left(100 \mathrm{MHz}, \mathrm{CDCl}_{3}\right): \delta 14.1$, 22.6, 26.3, 29.3, 29.6 (overlapping signals), 31.9, 33.6, 34.4, 69.4, 89.9, 95.0, 114.0, $116.1,125.2,132.9,133.4,134.1,139.7,142.2,153.5$.

7b. Yield: $23 \% . \quad{ }^{1} \mathrm{H}$ NMR $\left(400 \mathrm{MHz}, \mathrm{CDCl}_{3}\right): \delta 0.85(\mathrm{~s}, 6 \mathrm{H}), 1.22(\mathrm{~m}, 32 \mathrm{H}), 1.44(\mathrm{~s}$, $4 \mathrm{H}), 1.83(\mathrm{~m}, 4 \mathrm{H}), 2.86(\mathrm{br}, 2 \mathrm{H}), 3.04(\mathrm{br}, 2 \mathrm{H}), 3.30(\mathrm{br}, 2 \mathrm{H}), 3.79(\mathrm{br}, 2 \mathrm{H}), 3.91(\mathrm{br}$, $4 \mathrm{H}), 6.54(\mathrm{br}, 4 \mathrm{H}), 6.99(\mathrm{~m}, 2 \mathrm{H}), 7.21(\mathrm{~m}, 2 \mathrm{H}) .{ }^{13} \mathrm{C} \mathrm{NMR}\left(100 \mathrm{MHz}, \mathrm{CDCl}_{3}\right): \delta 14.1$, 22.7, 26.4, 29.2, 29.4, 29.7 (overlapping signals), 31.9, 33.7, 34.4, 69.4, 90.0, 94.9, 114.0, 116.2, 125.3, 132.9, 133.4, 134.2, 139.7, 142.3, 153.5.

7c. Yield: $18 \%$. ${ }^{1} \mathrm{H}$ NMR $\left(400 \mathrm{MHz}, \mathrm{CDCl}_{3}\right): \delta 0.87(\mathrm{~s}, 6 \mathrm{H}), 1.25(\mathrm{~m}, 48 \mathrm{H}), 1.44(\mathrm{~s}$, 4H), $1.83(\mathrm{~m}, 4 \mathrm{H}), 2.86(\mathrm{br}, 2 \mathrm{H}), 3.04(\mathrm{br}, 2 \mathrm{H}), 3.30(\mathrm{br}, 2 \mathrm{H}), 3.80(\mathrm{br}, 2 \mathrm{H}), 3.90(\mathrm{br}$, $4 \mathrm{H}), 6.54(\mathrm{br}, 4 \mathrm{H}), 6.99(\mathrm{~m}, 2 \mathrm{H}), 7.21(\mathrm{~m}, 2 \mathrm{H}) .{ }^{13} \mathrm{C} \mathrm{NMR}\left(100 \mathrm{MHz}, \mathrm{CDCl}_{3}\right): \delta 14.1$, 22.7, 26.4, 29.4, 29.7, 29.8 (overlapping signals), 32.0, 33.7, 34.4, 69.4, 90.0, 95.0, $114.1,116.1,125.3,133.0,133.4,134.2,139.7,142.3,153.6$.

\section{Model compound 8}

Ethynylxylene (0.32 g, $2.5 \mathrm{mmol}), 6 \mathbf{c}(0.70 \mathrm{~g}, 1.0 \mathrm{mmol}), \mathrm{PdCl}_{2}\left(\mathrm{PPh}_{3}\right)_{2}(71 \mathrm{mg}, 0.10$ $\mathrm{mmol})$, and $\mathrm{CuI}(18 \mathrm{mg}, 0.090 \mathrm{mmol})$ were placed in a Schlenk tube equipped with a magnetic stirring bar and a three-way cock. This tube was then purged with Ar followed by introducing THF $(5.0 \mathrm{~mL})$ and $\mathrm{Et}_{3} \mathrm{~N}(2.0 \mathrm{~mL})$. The reaction was carried out at $50^{\circ} \mathrm{C}$ overnight. After the reaction, ammonium salt was filtered off. The filtrate was dried and washed with $\mathrm{MeOH}$. The residue was subjected to $\mathrm{SiO}_{2}$ column (hexane $/ \mathrm{CH}_{2} \mathrm{Cl}_{2}, \mathrm{v} / \mathrm{v}=4 / 1$ as an eluent) to afford 8 as a pale yellow solid $(0.57 \mathrm{~g}, 0.81 \mathrm{mmol}, 81 \%)$.

$R_{f}=0.33\left(\mathrm{SiO}_{2}\right.$, hexane $\left./ \mathrm{CH}_{2} \mathrm{Cl}_{2}, \mathrm{v} / \mathrm{v}=4 / 1\right) .{ }^{1} \mathrm{H}$ NMR $\left(270 \mathrm{MHz}, \mathrm{CDCl}_{3}\right): \delta 0.88(\mathrm{t}, J$ $=7.6 \mathrm{~Hz}, 6 \mathrm{H}), 1.25-1.36(\mathrm{~m}, 32 \mathrm{H}), 1.51(\mathrm{~m}, 4 \mathrm{H}), 1.84(\mathrm{~m}, J=6.4 \mathrm{~Hz}, 4 \mathrm{H}), 2.31(\mathrm{~s}$, $3 \mathrm{H}), 2.51(\mathrm{~s}, 3 \mathrm{H}), 4.02(\mathrm{t}, J=6.4 \mathrm{~Hz}, 4 \mathrm{H}), 7.00(\mathrm{~s}, 2 \mathrm{H}), 7.04(\mathrm{~d}, J=8.0 \mathrm{~Hz}, 2 \mathrm{H}), 7.22$ $(\mathrm{d}, J=8.0 \mathrm{~Hz}, 2 \mathrm{H}), 7.33(\mathrm{~s}, 2 \mathrm{H}) .{ }^{13} \mathrm{C}$ NMR $\left(67.5 \mathrm{MHz}, \mathrm{CDCl}_{3}\right): \delta 14.1,20.2,20.7$, 22.7, 26.1, 29.3, 29.5, 29.6 (overlapping signals), 31.9, 69.5, 89.6, 94.1, 114.0, 116.5, 129.1, 129.3, 132.3, 134.9, 137.2, 153.5. Anal. Calcd. for $\mathrm{C}_{50} \mathrm{H}_{70} \mathrm{O}_{2}: \mathrm{C}, 85.41 ; \mathrm{H}$, 10.04. Found: $\mathrm{C}, 85.32 ; \mathrm{H}, 10.15$.

\section{Polymer 10}

Pseudo-para-diethynyl[2.2]paracyclophane 9 (10.3 mg, $40 \mu \mathrm{mol}), 6$ b $(33.5 \mathrm{mg}, 48$ $\mu \mathrm{mol}), \mathrm{Pd}\left(\mathrm{PPh}_{3}\right)_{4}(9.2 \mathrm{mg}, 8 \mu \mathrm{mol})$, and $\mathrm{CuI}(1.5 \mathrm{mg}, 8 \mu \mathrm{mol})$ were placed in a Schlenk tube equipped with a magnetic stirring bar and a three-way cock. This tube was then purged with $\mathrm{Ar}$ followed by introducing THF $(1.2 \mathrm{~mL})$ and $\mathrm{Et}_{3} \mathrm{~N}(1.2 \mathrm{~mL})$. The reaction was carried out at $75^{\circ} \mathrm{C}$ for $48 \mathrm{~h}$. After the reaction, ammonium salt was filtered off with celite and washed with THF. The combined organic solution was concentrated and washed with aqueous $\mathrm{NH}_{3}$ solution $(28 \%)$ to remove the inorganic species. The organic layer was dried over $\mathrm{Na}_{2} \mathrm{SO}_{4}$. The condensed organic layer was reprecipitated from $\mathrm{EtOH}$, and further reprecipitation from 
$\mathrm{CHCl}_{3} / \mathrm{EtOH}$ was carried out to obtain the corresponding polymer $\mathbf{1 0}$ as a yellow solid (18.4 mg, $26.4 \mu \mathrm{mol}, 66 \%)$.

${ }^{1} \mathrm{H}$ NMR $\left(270 \mathrm{MHz}, \mathrm{CDCl}_{3}\right): \delta 0.89(\mathrm{br}, 6 \mathrm{H}), 1.25-1.59(\mathrm{br}, 36 \mathrm{H}), 1.96(\mathrm{br}, 4 \mathrm{H})$, 2.94-3.05 (m, 4H), $3.36(\mathrm{~m}, 2 \mathrm{H}), 3.82(\mathrm{~m}, 2 \mathrm{H}), 4.14(\mathrm{br}, 4 \mathrm{H}), 6.43-6.55(\mathrm{~m}, 4 \mathrm{H})$, 7.06-7.16 (m, 4H). ${ }^{13} \mathrm{C}$ NMR $\left(67.5 \mathrm{MHz}, \mathrm{CDCl}_{3}\right): \delta 14.1,22.7,26.3,29.7$ (overlapping signals), 31.9, 34.1, 34.2, 69.6, 89.6, 95.2, 114.0, 116.3, 125.0, 130.3, $133.3,137.2,139.6,142.2,153.6$.

\section{Results and Discussion}

Scheme 1 outlines the synthetic procedure for the key monomer, pseudo-ortho-diethynyl[2.2]paracyclophane 5. Iron-catalyzed bromination of [2.2]paracyclophane $\mathbf{1}$ and successive recrystallization afforded only pseudo-para-dibromo[2.2]paracyclophane $\mathbf{2} \quad$ in $21 \%$ yield [8]. Pseudo-ortho-dibromo[2.2]paracyclophane $\mathbf{3}$ was obtained in $59 \%$ yield by the thermal isomerization of 2 at $220^{\circ} \mathrm{C}$ in triglyme [9]. Pseudo-ortho-diformyl[2.2] paracyclophane $\mathbf{4}$ was synthesized by treating $\mathbf{3}$ with $n$-BuLi and DMF in succession. Diformyl compound 4 was converted to pseudo-ortho-diethynyl[2.2]paracyclophane $\mathbf{5}$, by a method previously reported by Hopf and coworkers [9c]. Comonomers 6a-c were synthesized according to the literature's procedure [12].

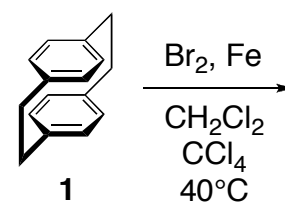

1

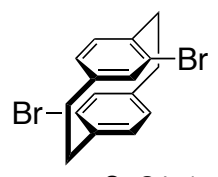

2, $21 \%$

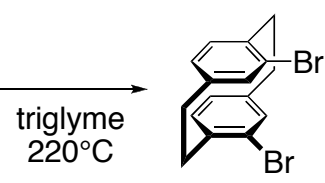

3, $59 \%$
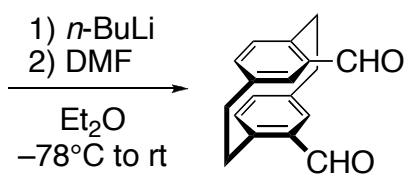

4, $53 \%$
1) $\left(\mathrm{Ph}_{3} \mathrm{P}-\mathrm{CHBr} 2\right) \mathrm{Br}$

2) $t$-BuOK

THF rt to $65^{\circ} \mathrm{C}$

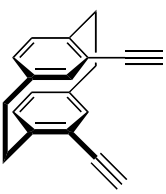

5, $52 \%$

Scheme 1. Synthesis of monomer 5
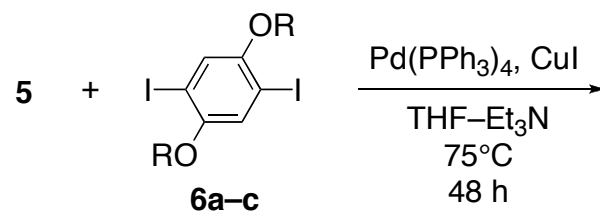

$$
\mathrm{R}=\left\{\begin{array}{l}
\mathbf{a} n-\mathrm{C}_{8} \mathrm{H}_{17} \\
\mathbf{b} n-\mathrm{C}_{12} \mathrm{H}_{25} \\
\mathbf{c} n-\mathrm{C}_{16} \mathrm{H}_{33}
\end{array}\right.
$$

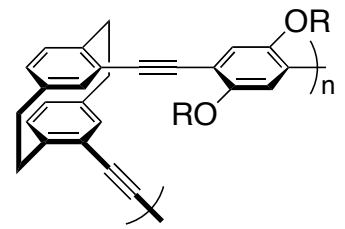

7a-c

Scheme 2. Synthesis of polymers $7 \mathbf{a}-\mathbf{c}$ 
Polymerization was carried out via the Sonogashira coupling reaction, as shown in Scheme 2, and the results are summarized in Table 1. Treatment of monomers $\mathbf{5}$ and 6a-c with a catalytic amount of $\mathrm{Pd}\left(\mathrm{PPh}_{3}\right)_{4} / \mathrm{CuI}$ in $\mathrm{THF}-\mathrm{Et}_{3} \mathrm{~N}$ yielded the corresponding polymers $\mathbf{7 a}-\mathbf{c}$ in $58 \%, 23 \%$, and $18 \%$ yields, respectively. Repeated purification of the crude polymers $7 \mathbf{a}-\mathbf{c}$ by reprecipitation from a $\mathrm{CHCl}_{3} / \mathrm{EtOH}$ solution resulted in moderate yields. Further purification by HPLC was carried out for polymers $\mathbf{7 b}$ and $\mathbf{7 c}$. The molecular weights of the polymers were measured by GPC $\left(\mathrm{CHCl}_{3}\right.$ : eluent) and estimated by using polystyrene standards (Table 1). The obtained polymers were dissolved in common organic solvents such as $\mathrm{CHCl}_{3}$, $\mathrm{CH}_{2} \mathrm{Cl}_{2}$, THF, and toluene. Thin films of these polymers were readily obtained by casting and spin-coating from one of the above mentioned solvents.

Table 1. Results of polymerization

\begin{tabular}{cccccc}
\hline Run & Polymer & Yield $^{a} \%$ & $M_{\mathrm{n}}{ }^{b}$ & $M_{\mathrm{w}}{ }^{b}$ & $M_{\mathrm{w}} / M_{\mathrm{n}}{ }^{b}$ \\
\hline 1 & $\mathbf{7 a}$ & 58 & 2000 & 3100 & 1.6 \\
2 & $\mathbf{7 b}$ & 23 & 3800 & 4900 & 1.3 \\
3 & $\mathbf{7 c}$ & 18 & 6400 & 8800 & 1.4 \\
\hline
\end{tabular}

${ }^{a}$ Isolated yield after reprecipitation at least three times.

${ }^{b} \mathrm{GPC}\left(\mathrm{CHCl}_{3}\right)$, polystyrene standards.

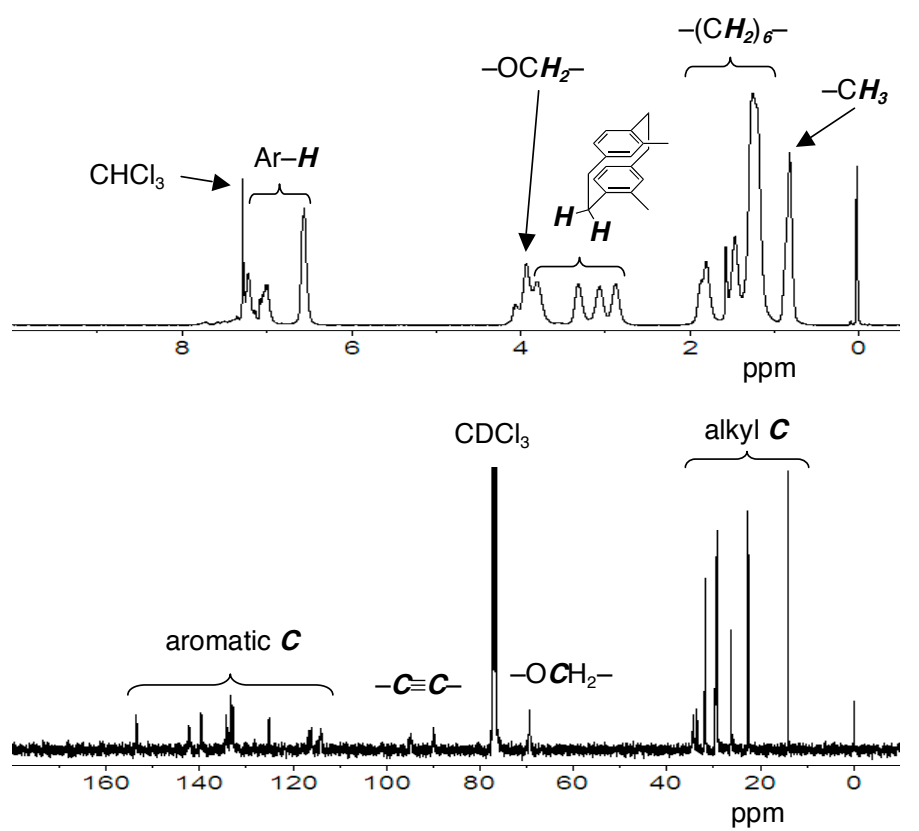

Figure 1. (A) ${ }^{1} \mathrm{H}$ NMR and (B) ${ }^{13} \mathrm{C}$ NMR spectra of polymer 7a in $\mathrm{CDCl}_{3}$.

The structures of polymers $7 \mathbf{a}-\mathbf{c}$ were confirmed by ${ }^{1} \mathrm{H}$ and ${ }^{13} \mathrm{C}$ NMR spectra. Figure 1 shows the ${ }^{1} \mathrm{H}$ and ${ }^{13} \mathrm{C}$ NMR spectra of polymer $7 \mathbf{a}$ in $\mathrm{CDCl}_{3}(400 \mathrm{MHz}$ and 
$100 \mathrm{MHz}$, respectively). In the ${ }^{1} \mathrm{H}$ NMR spectrum of 7a (Figure 1A), the signal due to the acetylene proton of monomer $\mathbf{5}$ at $3.28 \mathrm{ppm}$ completely disappeared, indicating the presence of dialkoxyphenyl moieties at the ends of the polymer chain. Signals at 0.8 ppm, 1.1-1.9 ppm, and $3.9 \mathrm{ppm}$ were assignable to the $-\mathrm{Me},-\left(\mathrm{CH}_{2}\right)_{6}-$, and $-\mathrm{OCH}_{2}-$ groups of the alkoxy side chains, respectively. The peaks of the bridged methylene protons belonging to the [2.2]paracyclophane units were observed at 2.8-3.8 ppm as four broad signals. Signals due to the aromatic protons in the [2.2]paracyclophane moieties appeared at 6.5 and $7.0 \mathrm{ppm}$, and aromatic protons in the alkoxybenzene units were observed at $7.2 \mathrm{ppm}$. In the ${ }^{13} \mathrm{C} N M R$ spectrum, typical signals of the carbon-carbon triple bond were observed at 90 and $95 \mathrm{ppm}$, as shown in Figure 1B.

The optical characteristics of the polymers $7 \mathbf{a}-\mathbf{c}$ were studied with the spectrophotometer and luminescence spectrometer; and compared with those of model compound $\mathbf{8}$ and through-space conjugated polymer $\mathbf{1 0}$ consisting of pseudo-para-linked [2.2]paracyclophane. Polymer 10 was synthesized in 66\% yield $\left(M_{\mathrm{n}}=6100\right)$ as shown in Scheme 3. The optical behaviors of polymers $7 \mathbf{a}-\mathbf{c}$ were identical irrespective of the length of their alkyl side chains. A summary of the optical properties is listed in Table 2. Figures 2 and 3 show the absorption and emission spectra of $\mathbf{7 b}, \mathbf{8}$, and $\mathbf{1 0}$ in dilute $\mathrm{CHCl}_{3}$. As shown in Figure 2, polymer $\mathbf{1 0}$, which possesses the pseudo-para-linked [2.2]paracyclophane moiety, had the highest absorption maximum at $386 \mathrm{~nm}$. This was red-shifted relative to polymer $\mathbf{7 b}$ and compound $\mathbf{8}$. However, the absorption spectra of polymers $\mathbf{7 b}$ and $\mathbf{1 0}$ exhibited no perceptible difference, while the spectrum of $7 \mathbf{b}$ exhibited a red-shift relative to that of 8. These observations are a direct consequence of the introduction of pseudo-ortho-linked [2.2]paracyclophane units into the polymer backbone, which resulted in the through-space conjugation in

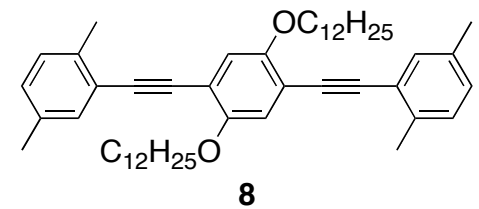
polymer $7 \mathbf{b}$.

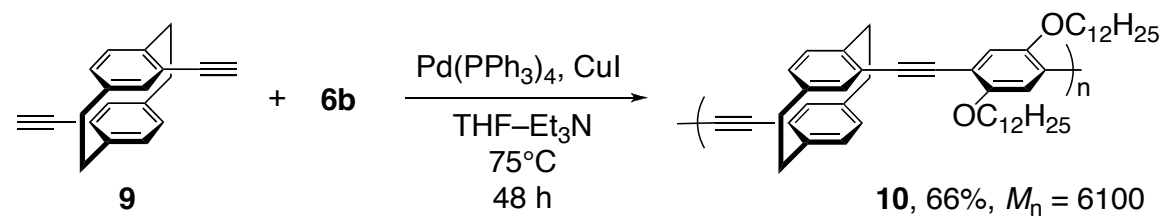

Scheme 3. Synthesis of polymer $\mathbf{1 0}$ containing pseudo-para-linked [2.2]paracyclophane

As can be seen from Figure 3, the fluorescence emission spectra of polymers $7 \mathbf{b}$ and 10 were almost similar, and an intense blue emission could be observed for both these polymers. The fluorescence quantum efficiencies of polymers $\mathbf{7 b}$ and $\mathbf{1 0}$ were found to be 0.86 and 0.82 (Runs 1 and 3, in Table 2), respectively, which were estimated from the quantum efficiency of the standard compound 9-anthracenecarboxylic acid. The fluorescence emission spectra of $\mathbf{7 b}$ and $\mathbf{1 0}$ were also red-shifted relative to the spectrum of model compound $\mathbf{8}$. 
Table 2. Optical properties of $\mathbf{7 b}, \mathbf{8}$, and $\mathbf{1 0}$

\begin{tabular}{ccccc}
\hline Run & Compound & Absorption $^{a} / \mathrm{nm}$ & Emission $^{b} / \mathrm{nm}$ & $\begin{array}{c}\text { Quantum }^{c} \\
\text { efficiency }^{c}\end{array}$ \\
\hline 1 & polymer 7b & 319,377 & 411,434 & 0.86 \\
2 & $\mathbf{8}$ & 320,369 & 398,417 & 0.86 \\
3 & polymer 10 & 319,386 & 414,438 & 0.82 \\
\hline
\end{tabular}

${ }^{a}$ In $\mathrm{CHCl}_{3}, 1.0 \times 10^{-5} \mathrm{M}$.

${ }^{b} \mathrm{In} \mathrm{CHCl}_{3}, 1.0 \times 10^{-7} \mathrm{M}$.

${ }^{c}$ Relative efficiency calculated by using 9 -anthracenecarboxylic acid as a standard.

On the other hand, the emission spectra of polymers $\mathbf{7 b}$ and $\mathbf{1 0}$ exhibited a clear vibrational structure, similar to the emission spectrum of $\mathbf{8}$ despite their $\pi$-stacked structures (Figure 3). This result indicates that polymers $\mathbf{7 b}$ and $\mathbf{1 0}$ emit blue light in their monomer state rather than in the phane state. In other words, the emission observed in the case of polymers $\mathbf{7 b}$ and $\mathbf{1 0}$ is not from the excimer but from the localized monomer unit $[2 \mathrm{e}-\mathrm{g}]$. The emission spectrum of thin film of polymer $\mathbf{7 b}$ was broad and red-shifted by approximately $40 \mathrm{~nm}\left(\lambda_{\max }=471 \mathrm{~nm}\right)$ relative to that of $7 \mathbf{b}$ in solution owing to the intermolecular $\pi-\pi$ interactions (Figure 3 ).

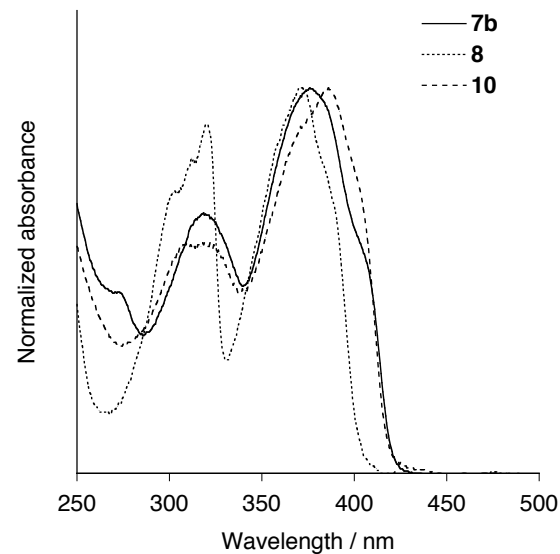

Figure 2. UV-vis absorption spectra of 7b, 8, and $\mathbf{1 0}$ in $\mathrm{CHCl}_{3}\left(1.0 \times 10^{-5} \mathrm{M}\right)$.

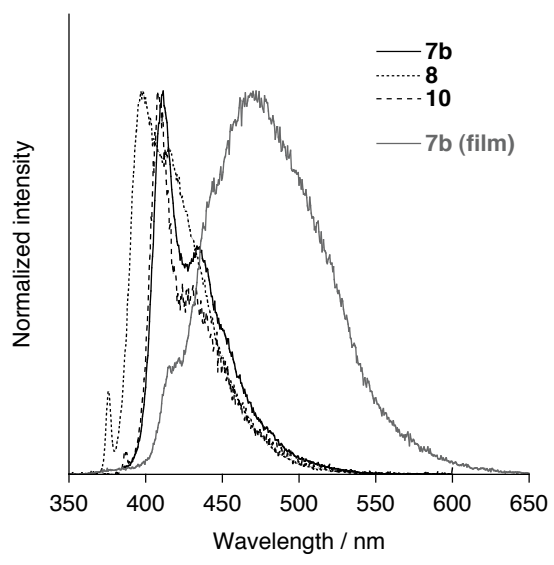

Figure 3. Fluorescence emission spectra of $7 \mathbf{b}$ in $\mathrm{CHCl}_{3}\left(1.0 \times 10^{-7} \mathrm{M}\right)$ and film, 8 in $\mathrm{CHCl}_{3}\left(1.0 \times 10^{-7} \mathrm{M}\right)$, and $\mathbf{1 0}$ in $\mathrm{CHCl}_{3}$ $\left(1.0 \times 10^{-7} \mathrm{M}\right)$ excited at each absorption maximum.

\section{Conclusion}

Through-space conjugated polymers consisting of pseudo-ortho-linked [2.2] paracyclophane were synthesized by the Sonogashira coupling reaction. The polymers exhibited an extension in the conjugation length via the through-space interaction of the [2.2]paracyclophane unit. An intense blue emission with a fluorescence quantum efficiency of 0.86 was observed from the localized monomer state of the polymer, irrespective of the $\pi$-stacked structure in the polymer chain. The optical profiles of these polymers were similar to those of the pseudo-para 
analogs; pseudo-ortho-disubstituted [2.2]paracyclophane can be used to synthesize foldamers and hold attraction of planar chirality. Our future research will be focused on synthesizing optically active through-space conjugated polymers with planar-chiral pseudo-ortho-linked [2.2]paracyclophane and investigating the higher-ordered structures of foldamers.

Acknowledgements. This work was supported by Grant-in-Aid for Creative Scientific Research of "Invention of Conjugated Electronic Structures and Novel Functions", No. 16GS0209, from the Ministry of Education, Culture, Sports, Science, and Technology, Japan.

\section{References}

1. Brown CJ, Farthing, AC (1949) Nature 164:915

2. (a) Cram DJ, Allinger, NL, Steinberg, H (1954) J Am Chem Soc 76:6132 (b) Heilbronner E, Yang ZZ (1983) Top Curr Chem 115:1 $\quad$ (c) Ganuto S, Zerner MC (1990) J Am Chem Soc 112:2114 (d) Yamakita Y, Yamauchi M, Ohno K (2000) Chem Phys Lett 322:189 (e) Oldham Jr WJ, Miao YJ, Lachicotte RJ, Bazan GC (1998) J Am Chem Soc 120:419 (f) Bazan GC, Oldham Jr WJ, Lachicotte RJ, Tretiak S, Chernyak V, Mukamel S (1998) J Am Chem Soc 120:9188 (g) Wang S, Bazan GC, Tretiak S, Mukamel S (2000) J Am Chem Soc 122:1289

3. (a) Vögtle F (1993) Cyclophane Chemistry. Wiley\&Sons, New York (b) Shultz J, Vögtle F (1994) Top Curr Chem 172:42 (c) Cleiter R, Hopf H, Eds. (2004) Modern Cyclophane Chemistry. Wiley-VCH, Weinheim

4. (a) Salhi F, Collard DM (2002) Polym Mater Sci Eng 222 (b) Salhi F, Collard DM $\begin{array}{lll}\text { (2003) Adv Mater 15:81 } & \text { (c) Guyard L, Audebert P (2001) Elecrochem Commun 3:164 }\end{array}$ (d) Guyard L, Nguyen Dinh An M, Audebert P (2001) Adv Mater 13:133

5. (a) Morisaki Y, Chujo Y (2006) Angew Chem Int Ed 45:6430 (b) Morisaki Y, Chujo Y (2008) Prog Polym Sci 33:346

6. (a) Morisaki Y, Chujo Y (2002) Macromolecules 35:587 (b) Morisaki Y, Chujo Y (2002) Chem Lett 194 (c) Morisaki Y, Ishida T, Chujo Y (2002) Macromolecules 35:7872 (d) Morisaki Y, Chujo Y (2002) Polym Bull 49:209 (e) Morisaki Y, Fujimura F, Chujo Y (2003) Organometallics 22:3553 (f) Morisaki Y, Chujo Y (2003) Macromolecules 36:9319 (g) Morisaki Y, Chujo Y (2004) Macromolecules 37:4099 (h) Morisaki Y, Ishida T, Tanaka H, Chujo Y (2004) J Polym Sci Part A Polym Chem 42:5891 (i) Morisaki Y, Wada N, Chujo Y (2005) Polym Bull 53:73 (j) Morisaki Y, Wada N, Chujo Y (2005) Polymer 46:5884 (k) Morisaki Y, Chujo Y (2005) Bull Chem Soc Jpn 78:288

7. (a) Morisaki Y, Chujo Y (2005) Tetrahedron Lett 46:2533 (b) Morisaki Y, Murakami T, Chujo Y (2008) Macromolecules 41:5960

8. $\quad$ Reich HJ, Cram DJ (1969) J Am Chem Soc 91:3527

9. (a) Pye PJ, Rossen K, Reamer RA, Tsou NN, Volante RP, Reider PJ (1997) J Am Chem Soc 119:6207 (b) Braddock DC, MacGilp ID, Perry BG (2002) J Org Chem 67:8679 (c) Bondarenko L, Dix I, Hinrichs H, Hopf H (2004) 16:2751

10. Pangborn AB, Giardello MA, Grubbs RH, Rosen RK, Timmers FJ (1996) Organometallics 15:1518

11. Wolkoff P (1975) Can J Chem 53:1333

12. Li H, Powell DR, Hayashi RK, West R (1998) Macromolecules 31:52 